PAZ, H. (2003): Root/shoot allocation and root architecture in seedlings: Variation among forest sites, microhabitats, and ecological groups. Biotropica 35: 318-332.

Poorter, H. and O. NAGEL (2000): The role of biomass allocation in the growth response of plants to different levels of light, $\mathrm{CO}_{2}$, nutrients and water: a quantitative review. Australian Journal Plant Physiology 27: 595-607.

Retzlaff, W. A., J. A. Handest, D. M. O’Malley, S. E. McKeAND and M. A. TopA (2001): Whole-tree biomass and carbon allocation of juvenile trees of loblolly pine (Pinus taeda): influence of genetics and fertilization. Canadian Journal of Forest Research 31: 960-970.

RUNE, G. (2003): Slits in container wall improve root structure and stem straightness of outplanted Scots pine seedlings. Silva Fennica 37: 333-342.

Sonesson, J., G. JANSSON and G. ERIKSSON (2001): Retrospective genetic tests of Pinus sylvestris L. in growth chambers with two irrigation regimes and two temperatures. Scand J Forest Res. 16: 21-29.
South, D. B., S. W. Harris, J. P. Barnett, M. J. Hainds and D. H. GJERSTAD (2005): Effect of container type and seedling size on survival and early height growth of Pinus palustris seedlings in Alabama, USA. Forest Ecology and Management 204: 385-398.

Thiffault, N. (2004): Stock type in intensive silviculture: A (short) discussion about roots and size. Forestry Chronicle 80: 463-468.

WANG, E. L. and C. J. SMith (2004): Modelling the growth and water uptake function of plant root systems: a review. Australian Journal of Agricultural Research 55: 501-523.

Zas, R., E. Merlo and J. FernandeZ-Lopez (2004): Juvenile - Mature genetic correlations in Pinus pinaster Ait. under different nutrient $\mathrm{x}$ water regimes. Silvae Genet. 53: 124-129.

Zhang, X., N. Wu and C. Li (2005): Physiological and growth responses of Populus davidiana ecotypes to different soil water contents. Journal of Arid Environments 60: $567-579$.

\title{
Spatial Genetic Structure Within Two Contrasting Stands of Scots Pine (Pinus sylvestris L.)
}

\author{
By I. J. Chybicki $\left.{ }^{1)}{ }^{*}\right)$, A. Dzialuk ${ }^{1)}$, M. Trojankiewicz ${ }^{1)}$, M. Slawski ${ }^{2)}$ and J. Burczyk ${ }^{1)}$
}

(Received $3^{\text {rd }}$ January 2007)

\begin{abstract}
When considering neutral nuclear markers, genetic differentiation of Scots pine (Pinus sylvestris L.) populations is known to be low. The homogeneity arises particularly as an effect of common ancestry in a recent evolutionary history as well as an extensive gene flow, especially through pollen. However, within populations several other forces may shape the spatial distribution of genetic variation, including establishment history, environmental and silvicultural selection. These local forces are known to produce non-random spatial patterns of genetic variation, however little is known on fine-scale spatial genetic structure of Scots pine. In this study, two stands of this species with different establishment histories, selected within one larger population located in northern Poland were genotyped and analysed for genetic variation and within-stand spatial genetic structure. Results revealed no differences in genetic variation, although stands are separated about $60 \mathrm{~km}$, suggesting that the two populations share a common genet-

1) Department of Genetics, Institute of Biology and Environmental Protection, Kazimierz Wielki University of Bydgoszcz, Bydgoszcz 85-064, Poland.

$\left.{ }^{2}\right)$ Department of Forest Protection and Ecology, Faculty of Forestry, Warsaw Agricultural University, Warsaw 02-787, Poland.

*) Communicating author. Telephone: +48-52-3419281. Fax: +4852-3608391. E-mail: igorchy@ukw.edu.pl
\end{abstract}

ic pool. The spatial genetic structure in both stands was found to be slightly different and was attributed to differences in the mode of populations' establishments. Finally, results confirmed that gene flow in Scots pine is extensive, causing genetic homogeneity within a single population.

Key words: genetic structure, spatial autocorrelation, relatedness coefficient, forest management, colonization, Scots pine.

\section{Introduction}

When considering neutral nuclear markers, the genetic variation of Scots pine (Pinus sylvestris L.) is generally high and accumulated mainly within populations, while genetic differences among populations are fairly small (PRUS-GLOWACKI et al., 1993; GONCHARENKO et al., 1994b; DvORNYK, 2001). Only marginal populations, especially from Iberian Peninsula, reveal significant genetic divergence from the rest of European populations (PRUs-GLOWACKI and STEPHAN, 1994; DvorNYK et al., 2002). The homogeneous nature of a macro-geographical variation might arise primarily as an effect of a common ancestry in a recent evolutionary history of the species (GULlBERG et al., 1985). Because pollen of Scots pine has a great mobility potential (LINDGREN et al., 1995), the homogeneity could be easily maintained over distances. However, at a local scale many other fac- 
tors such as seed dispersal, silvicultural treatment or establishment history, may influence demographic and genetic structure of a stand (EPPERSON, 1992). This aspect is interesting for Scots pine, which is of great commercial importance. Silvicultural management, including seed collection, reforestation methods or selective thinning may be a critical factor in shaping patterns of genetic variation. Despite various genetic consequences of local forces, within-stand spatial genetic structure of Scots pine is still incompletely characterized.

Population genetics, starting with the theory of isolation-by-distance (WRIGHT, 1943), has provided general characteristics of structured populations (e.g. SoKAL and WARTENBERG, 1983; EPPERSON, 1995; ROUSSET, 2000). If propagule dispersal is somehow limited, individuals mate predominantly within small neighbourhoods. In effect, after a number of generations the level of homozygosity is expected to increase. Successive decline of genetic diversity may result in negative consequences such as inbreeding depression or decreased adaptation capabilities (KäRKKÄINEN and SAVOLAINEN, 1993; KOELEWIJN et al., 1999).

Spatial genetic structure has been already studied within populations of different forest tree species, including many conifers. Generally, results suggest that the spatial genetic structure of adult trees is rather weak (e.g. EPPERSON and ALLARD, 1989; LEONARDI and Menozzi, 1996; PARKer et al., 2001; EPPERSON and Chung, 2001). The usual explanation for this phenomenon is an extensive gene flow through pollen, especially in wind-pollinated species. Nonetheless, there are some evidences of genetic patchiness of forest trees caused mainly by limited seed dispersal (Pinus pinaster seedling stage, GONZALEZ-MARTINEZ et al., 2002), vegetative reproduction (Atherospermum moschatum, SHAPCOTT, 1995) or patchily distributed soil moisture (Pinus edulis, MitTon et al., 1998).

The special attention has been paid to assessing the level of spatial genetic structuring as a result of differ- ent establishment histories of forest tree populations. Results provided for different species allow to conclude that as long as reforestation process is based on a natural seed dispersal and seedling recruitment, the spatial genetic structure of a stand is dependent primarily on two factors, i.e. a size of maternal population and the potential of seed dispersal, which is a species dependent characteristics (KNOWLES et al., 1992; TAKAHASHI et al., 2000, EpPerson and ChUnG, 2001; PARKER et al., 2001; Jones et al., 2005; GEBUREK, 2005). For example, a stand established using the seed-tree method (when a number of mother-trees is limited) is expected to reveal the stronger spatial autocorrelation of genes than the one established after a clear-cut and colonization form off-site sources (e.g. KNOWLES et al., 1992; TAKAHASHI et al., 2000). Furthermore, the tendency will be stronger for species characterized by limited seed dispersal (JONES et al., 2005; VEKEMANS and HARDY, 2004), although dispersal intensity might be specific to a given site. For example, a presence of Sasa cover under canopy of Quercus mongolica promotes secondary dispersal of acorns, leading to a weaker spatial genetic structure when comparing to a population free of Sasa cover (CHUNG and CHUNG, 2004). The factors defined above shape the primary spatial genetic structure. However, as a stand age increases secondary factors including management practices (e.g. logging or thinning) start to play an important role (EPPERSON, 1992). However, up to now there is a little evidence for negative or positive impact of management practices on the spatial genetic structure. For example, the small-scale structuring could be easily removed by intense logging (EPPERSON and CHUNG, 2001).

In this study we investigated the spatial genetic structure of two contrasting stands of Scots pine located within one continuous population: (i) the even aged qualified seed-tree stand utilized for commercial seed collections and (ii) the naturally established unevenaged and unmanaged stand. Our null hypothesis assumes that regardless of differences in silvicultural
Woziwoda

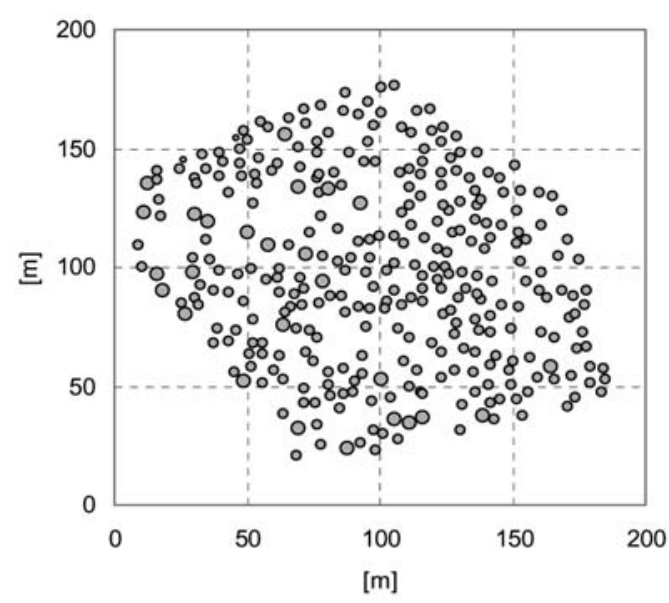

Stara Brda

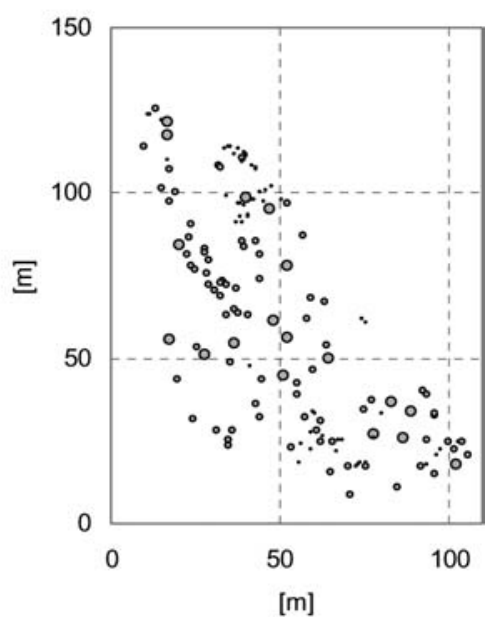

Figure 1. - Sampling maps of studied stands. Different circle sizes correspond to variation in tree diameter at breast height. 
treatment the studied stands are weakly genetically differentiated as well as there is no difference in a spatial genetic structure, which is expected to be low (if any) in both stands.

\section{Materials and Methods}

\section{Study sites and material}

The two Scots pine stands selected for this study are located about $60 \mathrm{~km}$ apart in northern Poland, within a greater coniferous complex, the Tuchola Forests (Table 1). The first stand 'Woziwoda' is a qualified seed-tree stand being under silvicultural management of the forest district Woziwoda. This pure even-aged stand (about 160 years old) covers 4 ha in a typical subboreal habitat and is surrounded by younger (40-80 yrs old) managed stands of Scots pine. The information on the establishment history of the stand is not available because most of the records of the Woziwoda forest district were lost probably during the First World War. However, a verbal communication and historical facts point at a natural regeneration method. The Woziwoda stand is exemplarily managed being recently under a strong human impact, including intensive selective thinning according to the standards for seed tree stands. It is worth noting that there are many plus trees and two elite trees within the Woziwoda stand. It is considered an important commercial seed source providing seeds for local and regional reforestations, with a number of progeny plantations established. The second stand 'Stara Brda', on the other hand, is an uneven-aged (from 20-100 years old) population occupying about 0.7 ha of a drying peatbog and is surrounded immediately by grasslands and at larger distances (50-200 meters) by other Scots pine stands. This specific habitat has never been managed and was colonized by Scots pine without human interference. However, the stand's age structure suggests a long (dozens of years) process of settling. From silvicultural point of view, the trees from the Stara Brda stand have a low phenotypic value as compared to trees from the Woziwoda stand. However, the low quality of the Stara Brda stand can be explained rather by the absence of management practices than by the genetic effect, although the latter one cannot be absolutely excluded.

In winter 1999, a sample plot of 2.1 ha in size embracing 321 individual trees was established within the Woziwoda stand. In the case of Stara Brda the entire stand was considered as a study plot, which included 173 trees. In both plots all trees were mapped and sampled for cones, eventually for needles for genotyping purposes. Additionally, the trunk diameter at breast height ( $d b h)$ of each sampled tree was measured (Fig. 1, Fig. 2). Here, $d b h$ distribution was used for a rough visualization of the spatial age structure because the diameter of a tree is known to be highly correlated with its age and such measurement is neither costly nor invasive.

Genetic variation at 14 allozyme loci (Fest, Gdh, Aat-1, Aat-2, Aat-3, Mdh-1, Mdh-3, Mdh-4, 6Pgdh-1, 6Pgdh-2, Pgi-2, Pgm-1 and Shdh-1) was studied using standard starch gel electrophoresis methods (RUDIN and

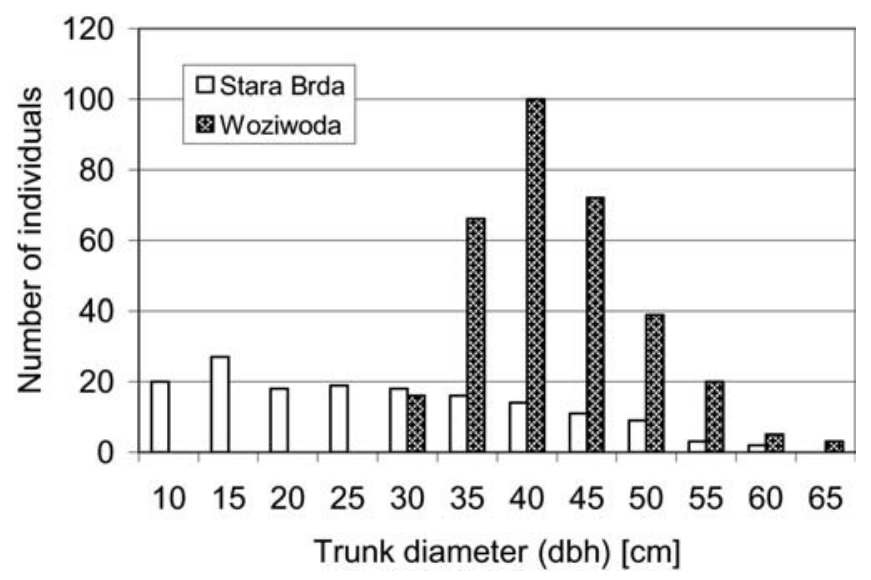

Figure 2. - Distribution of the trunk diameter $(d b h)$ in studied stands.

Ekberg, 1978; Conkle et al., 1982; Cheliak and Pitel, 1985), with slight modifications.

\section{Data analysis}

Genetic variation of populations was assessed by observed $(A)$ and effective $\left(A_{e}\right)$ number of alleles per locus, observed $\left(H_{o}\right)$ and expected $\left(H_{e}\right)$ heterozygosity and the Wrigth's fixation index $(F)$. The estimates of fixation indices for particular loci were statistically tested for deviations from Hardy-Weinberg equilibrium using chi-square test according to equation $\hat{\chi}^{2}=\left(n_{a}-1\right) F^{2} \mathrm{~N}$, where $N$ is a number of genotyped individuals and $n_{a}$ is a number of alleles at a given locus. The test statistic $\hat{\chi}^{2}$ has chi-square distribution with $n_{a}\left(1-n_{a}\right) / 2$ degrees of freedom (LI and HoRviTZ, 1953). Calculations (except chi-square tests) were conducted using PopGene ver. 1.32 software (YEH et al., 1997) available on the web site http://www.ualberta.ac/ fyeh. Also, $F_{S T}$ coefficient was estimated as an indicator of population differentiation and tested using a randomization test (without H.-W. assumption) implemented in FSTAT 2.9.3 computer program (GOUDET, 1995).

In order to describe spatial genetic structure we performed a spatial autocorrelation analysis. For this purpose the multilocus and multiallelic relatedness coefficient was employed, which for the $h$-th distance class was estimated according to equation (STREIFF et al., 1998):

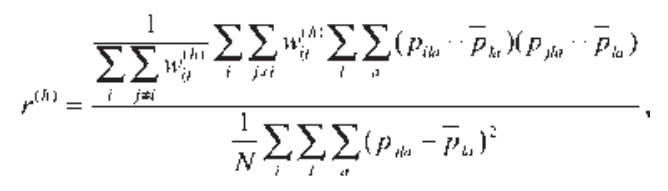

where $w_{i j}^{(h)}$ equals 1 when the distance between the $i$-th and the $j$-th individual falls into the $h$-th distance class, and 0 otherwise, $p_{i l a}$ and $p_{j l a}$ are frequencies of the $a$-th allele at the $l$-th locus in the $i$-th and the $j$-th individuals, respectively, and $\bar{p}_{l a}$ is a sample frequency of the $a$-th allele at the $l$-th locus. It is worth noting that the relatedness measure described above is asymptotically equal to the unweighted autocorrelation coefficient introduced by SMOUSE and PEAKALL (1999). We preferred the Streiff and co-authors' formula mainly because it is 
Table 1. - Characteristics of the studied stands.

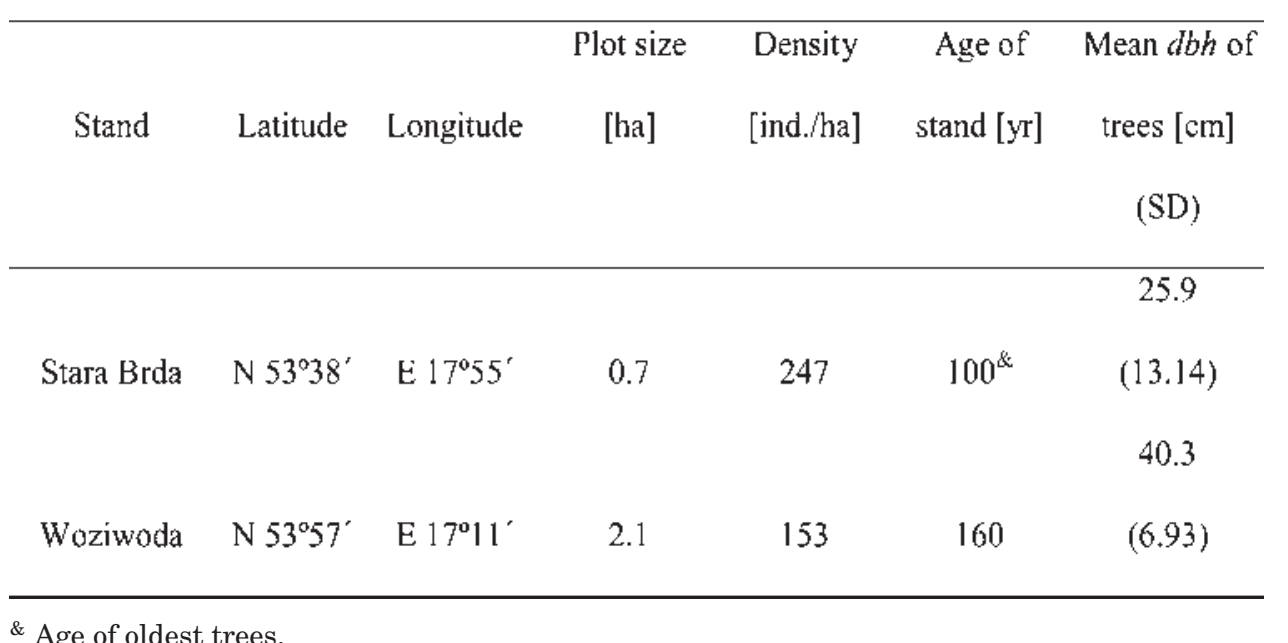

\& Age of oldest trees.

closely related to the Moran's I coefficient, as well as it stays in the relationship with the kinship coefficient $f$ (LOISELLE et al., 1995) of form $r=2 f /(1+F)$, where $F$ is the Wright's inbreeding coefficient. For details the reader should refer to the Appendix. Average relatedness measures obtained across a series of distance classes provides a specific plot (correlogram) presenting changes of average genetic similarity between any two individuals with increasing distance. Because the strength of autocorrelation between nearest neighbours is usually used as an indicator of a spatial genetic structure (VEKEMANS and HARDY, 2004; EPPERSON, 2005), the size of a distance class has to be chosen carefully. Therefore, in the present study a distance class size was computed according to the nearest neighbour criterion for a nonlattice sampling, i.e. $\sqrt{2 / \mathrm{D}}$ (where $D$ is a stand density) (EPPERSON, 2005). Hence, the distance class size was set to 9 meters for Stara Brda and to 12 meters for Woziwoda (see Table 1). Autocorrelation analysis was performed under a null hypothesis of the absence of spatial autocorrelation. Usually, to test this hypothesis one may check whether the estimate of autocorrelation statistic was drawn from the null distribution with the mean $\mu=0$ and the specific variance $\sigma^{2}$ (CLIFF and ORD, 1981). Because the variance of the null distribution of the multilocus $r^{(h)}$ statistics needs measures of covariance between single-allele coefficients, which are computationally demanding (EPPERSON, 2004), instead a permutational test was applied, which provides a confidence interval around expected autocorrelation estimates under a null hypothesis. Such confidence intervals were obtained with 10000 permutations of positions of genotypes within a population. Spatial autocorrelation analyses were performed using the user-friendly computer program SpA written in Delphi 7 (Borland Inc.) (available from I.J.C.).

To assess whether the studied stands differ in demographic history, the effective population size $\left(N_{e}\right)$ was estimated using the reciprocal relationship between $N_{e}$ and the level of gametic disequilibrium, measured as the squared correlation of allele frequencies at different loci $\left(\rho^{2}\right)$. Providing that loci are unlinked and $N_{e}$ as well as $N$ are large, the relationship takes approximately the form:

$$
\rho^{2}=\frac{1}{3 N_{1}}+\frac{1}{N}
$$

where $N$ is a number of genotyped individuals (WEIR and HiLL, 1980). However, when $N_{e}>N$, (which might be possible in our case, see e.g. BuRCZYK, 1996; DvORNYK et al., 2002), the $\rho^{2}$ is more related to a sample size than the effective population size, causing severely biased and imprecise (large variances) estimates of $N_{e}$ (ENGLAND et al., 2006). In order to improve the estimator of effective population size, the empirical correction of the relationship can be applied (WAPLES, 2006), so the effective population size is obtained as follows:

$$
\hat{N}_{e}=1 / 3+\frac{1 / 9-2.76\left(\hat{\rho}^{2}-1 / N-3.19 / N^{2}\right)}{2\left(\hat{\rho}^{2}-1 / N-3.19 / N^{2}\right)} .
$$

where $\hat{\rho}^{2}$ is the estimate of $\rho^{2}$ calculated as a mean over all two-locus allelic combinations (WAPLES, 1991; WAPLES, 2006). Additionally, because the relationship between $\rho^{2}$ and $N_{e}$ is sensitive to the distribution of allele frequencies (HUDSON, 1985), in this study the alleles with frequency lower than 0.05 were excluded from the computation of $\hat{\rho}^{2}$ (WAPLES, pers. comm.). The confidence intervals around $\hat{N}_{e}$ were calculated using the bootstrap procedure by sampling with replacement from the original sample of single two-locus $\hat{\rho}^{2}$ coefficients. Afterwards, in order to test whether the studied stands differ in $N_{e}$, the two-locus sets of $\hat{\rho}^{2}$ coefficients estimated for each population were merged. Then, from the pooled set of $\hat{\rho}^{2}$ values two bootstrap samples were drawn with replacement and their means were computed. $\hat{N}_{e}$ values were estimated based on bootstrap sample means and then the absolute difference in $\hat{N}_{e}$ between two bootstrap samples was scored. The approximate null distribution of the difference between the two means was formulated by repeating of the above procedure 10000 times. The null hypothesis at a significance level $\alpha$ is rejected when the observed difference in $\hat{N}_{e}$ between the studied stands falls outside the $(1-\alpha) 100$-th percentile of the null distribution. It should be stressed 
Table 2. - Parameters of genetic structure of Stara Brda and Woziwoda stands: $A$ - number of alleles, $A_{e}$ - effective number of alleles, $H_{e}$ - expected heterozygosity, $H_{o}$ - observed heterozygosity and $F-$ Wright's coefficient of fixation.

\begin{tabular}{|c|c|c|c|c|c|}
\hline Locus & $A$ & $A_{i^{\prime}}$ & $H_{4^{\prime}}$ & $W_{a}$ & $F$ \\
\hline \multicolumn{6}{|c|}{ Stara Brda } \\
\hline $6 P g d h-2$ & 3 & 1.87 & 0.467 & 0.451 & 0.035 \\
\hline Aat-1 & 2 & 1.03 & 0.029 & 0.029 & -0.015 \\
\hline$A a t-2$ & 4 & 2.12 & 0.528 & 0.486 & 0.080 \\
\hline$A_{a t-3}$ & 2 & 1.90 & 0.475 & 0.393 & $0.172 *$ \\
\hline$G d h$ & 2 & 1.91 & 0.477 & 0.555 & $-0.163^{*}$ \\
\hline$M d h-l$ & 2 & 1.17 & 0.149 & 0.058 & $0.611 * *$ \\
\hline$M d h-3$ & 2 & 1.66 & 0.398 & 0.410 & -0.030 \\
\hline$M d h-4$ & 4 & 2.14 & 0.533 & 0.462 & 0.132 \\
\hline Shdh-7 & 4 & 1.43 & 0.305 & 0.249 & 0.185 \\
\hline Mean & 2.8 & 1.70 & 0.374 & 0.344 & $0.112^{*}$ \\
\hline \multicolumn{6}{|c|}{ Woziwoda } \\
\hline $6 P g d h-l$ & 4 & 2.06 & 0.514 & 0.554 & -0.078 \\
\hline $6 P g d h-2$ & 4 & 1.74 & 0.424 & 0.415 & 0.022 \\
\hline Aat-l & 3 & 1.04 & 0.037 & 0,037 & -0.015 \\
\hline$A a t-2$ & 5 & 2.10 & 0.524 & 0.598 & $-0.141^{* * *}$ \\
\hline $\operatorname{Aat}-3$ & 6 & 1.95 & 0.488 & 0.502 & -0.029 \\
\hline Fest & 4 & 1.71 & 0.414 & 0.401 & 0.033 \\
\hline$G d h$ & 2 & 1.88 & 0.468 & 0.492 & -0.051 \\
\hline Mdh-1 & 2 & 1.08 & 0.081 & 0.084 & -0.044 \\
\hline$M d h-3$ & 4 & 1.80 & 0.445 & 0.467 & -0.050 \\
\hline$M d h-4$ & 5 & 2,35 & 0.575 & 0.620 & -0.078 \\
\hline$M n r$ & 3 & 1.99 & 0.497 & 0.477 & 0.041 \\
\hline Pgi-2 & 4 & 1.51 & 0.337 & 0.362 & -0.074 \\
\hline$P g m-I$ & 2 & 1.06 & 0.058 & 0.060 & -0.031 \\
\hline Shdh-l & 4 & 1.49 & 0.330 & 0.316 & 0.043 \\
\hline Mean ${ }^{3}$ & 3.7 & 1.70 & 0.371 & 0.385 & -0.032 \\
\hline $\operatorname{Mean}^{2}$ & 3.9 & 1.71 & 0.375 & 0.392 & -0.038 \\
\hline
\end{tabular}

*) $\alpha<0.05, * *) \alpha<0.01$.

${ }_{1}^{1}$ Mean computed over all fourteen loci.

${ }^{2}$ Mean computed over a subset of nine loci analyzed both in Stara Brda and Woziwoda. 
that the estimation of an effective population size described above is valid as long as there is a free recombination between all pairs of loci. The isozyme markers studied here generally meet the above assumption (RUDIN and EKBERG, 1978; NIEBLING et al., 1987; SzMIDT and MuONA, 1989; GonCHARENKo et al., 1994a), although there was a concern about two pairs of loci, i.e. $6 P g d h-1$ and $M d h-1$ as well as Aat-3 and $6 P g d h-1$, which were reported as linked by NIEBLING and co-authors (1987) (28.3 and $25.3 \mathrm{cM}$, respectively), while as not linked by GONCHARENKO and others (1994a). Nevertheless, these two pairs of loci were excluded from the estimation of $N_{e}$.

\section{Results}

\section{Genetic structure}

Data for all fourteen enzymatic loci were collected for Woziwoda, whereas for Stara Brda, where seeds and needles (diploid tissue) were sampled for genotyping purposes, only nine loci were used, which gave clear and unambiguously interpretable results (Tab. 2). We observed the difference between the studied stands in the level of polymorphism corresponding to the actual number of alleles $(A)$. However, the higher number of alleles in Woziwoda may be explained by twice as large sample size for Woziwoda than for Stara Brda. The mean effective number of alleles $\left(A_{e}\right)$ clearly showed similar polymorphism within the two studied stands. Also, we observed no difference in the level of genetic diversity measured by expected heterozygosity $\left(H_{e}\right)$. The distinction between the populations occurred particularly in the level of inbreeding evaluated by Wright's fixation indices. In Woziwoda the fixation index was on average slightly lower than zero and only Fest, Mnr, 6Pgdh-2 and Shdh-1 out of 14 loci exhibited deficiency of heterozygotes. Stara Brda had the estimates of fixation index ranging from -0.1670 to 0.6114 with an average equal to 0.112 . As revealed by Chi-square test, Woziwoda did not exhibit (except Aat-2) the deviation of fixation indices from expected zero, while for Stara Brda we observed strong deviations at four loci (i.e. $G d h$, Aat-3, Mdh-1, Shdh-1).

Genetic differentiation between the studied Scots pine population appeared to be fairly low as indicated by $F_{\mathrm{ST}}$, which ranged from $0.01 \%$ for Aat-3 to $0.65 \%$ for $M d h-1$, with an average equal to $0.2 \%$. Only two loci revealed significant $(\alpha=0.05) F_{\mathrm{ST}}$ estimates (Mdh-1 and $\left.M d h-4\right)$. Nonetheless, a randomization test showed that there is a significant differentiation between the two stands at a multilocus level ( $p$-value $<0.001)$.

\section{Spatial autocorrelation}

Spatial autocorrelation was measured for single loci and for multilocus data. For both stands, single locus statistics were not concordant among each other suggesting quite complex spatial distribution of genes (data not shown). Also, there was no correlation between spatial autocorrelation and particular parameters of genetic structure at particular loci. Because autocorrelation coefficients for the first distance class are of special interest, here we focus particularly on them. For the

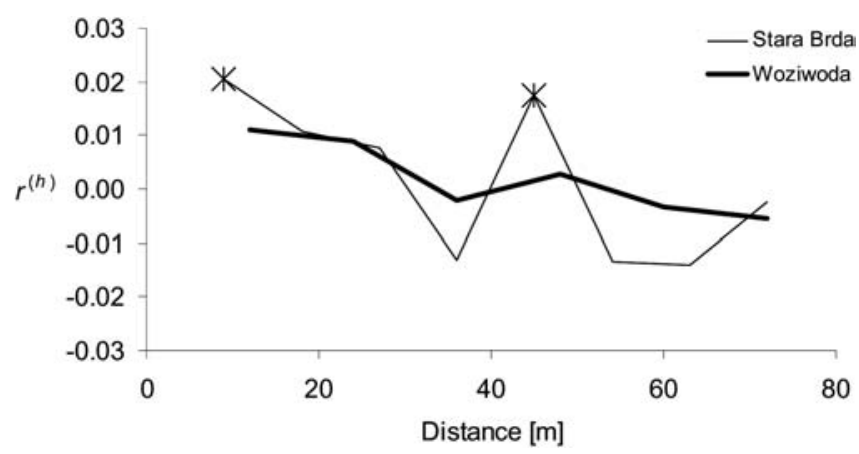

Figure 3. - Correlograms showing spatial autocorrelation of multilocus genetic structure for Woziwoda and Stara Brda stands. Asterisks denote statistically significant $(\alpha=0.05)$ autocorrelation values.

Woziwoda stand in the first distance class three indices out of fourteen were significantly different from zero, with two of them (i.e. Aat-1 and $M d h-3$ ) exhibiting a positive spatial autocorrelation. Also a positive multilocus spatial autocorrelation was observed up to 24 meters, however all 6 multilocus autocorrelation coefficients were not significantly different from zero ( $\alpha=0.05$ ), as revealed by permutation tests (Fig. 3). In the case of Stara Brda stand a positive single-locus spatial autocorrelation was observed for 4 out of 9 loci in the first distance class, and one exhibited significant difference from zero (Aat-3). The multilocus correlogram for Stara Brda indicated a very weak but significant spatial structure (Fig. 3). Interestingly, a statistically significant positive autocorrelation was here observed also for the fifth distance class $(36-45 \mathrm{~m})$. Concerning the shape of the correlogram, in the case of Woziwoda the pair-wise relatedness decays approximately monotonically together with the distance. On the other hand, for Stara Brda the relationship between the distance and the relatedness was markedly irregular, although the regression analysis revealed decrease in relatedness between individuals together with the increase of the distance (data not shown).

\section{Effective population size}

The level of gametic disequilibrium measured within Woziwoda stand corresponded to the effective population size equal to 148.6 , with the $95 \%$ confidence interval between 100.7 and 278.3. For Stara Brda stand the estimate of $N_{e}$ was much lower than the estimate for Wozowoda and accounted for 89.2 with the $95 \%$ confidence interval between 45.2 and 307.1. The difference in $N_{e}$ estimates between the two stands was found to be 59.4 , being however not significant, as revealed by the bootstrap test $(p$-value $=0.675)$.

\section{Discussion}

We investigated the two stands of Scots pine differing in their colonization history and stand structure. Both stands revealed a high level of genetic polymorphism which is comparable to other populations of this species (GullberG et al., 1985; Prus-GlowaCKI et al., 1993). Although there were some discrepancies in census num- 
ber of alleles at several loci, genetic diversity of both stands was strikingly similar. Nonetheless, the two stands differed substantially in the levels of inbreeding. In theory, for long-lived predominantly outcrossing species fixation index is expected to be slightly positive (SPIESS, 1989), though in natural populations of Scots pine fixation index can decrease to negative values in time (YAZDANI et al., 1985). In Woziwoda we observed a small negative fixation index, while in Stara Brda it was highly positive at some loci, suggesting the substantial inbreeding in the recent history. Nonetheless, because the mating system should influence all neutral loci more or less equally, one explanation of the overall significant deficit of heterozygotes in Stara Brda could be a temporary Wahlund effect (EPPERSON and CHUNG, 2001), i.e. an effect of mixing divergent genetic pools within one sample. The age structure of Stara Brda supports that this could take a place as a result of a long time of colonization of a new habitat.

The estimated $F_{\text {ST }}$ coefficients also showed that the two studied stands genetically are not very differentiated at the single locus level (although at the multilocus genotypic level they are), confirming that neutral genetic variation of Scots pine is fairly well represented within a single population (PRUS-GLOWACKI et al., 1993). Thus, a landscape-level genetic structure of the studied population seems very low, suggesting that gene flow over a distance of dozens of kilometres can be substantial, especially in continuous forests.

Although Scots pine is one of the most important forest trees, to our knowledge this study is the first attempt to characterize the within-stand spatial genetic structure of this species. A number of similar studies indicated that spatial autocorrelation is generally very weak in conifers, mostly due to high levels of pollen, but often also seed dispersal (e.g. EPPERSON and ALLARD, 1989; EPPERson and ChUnG, 2001; Gonzalez-MARTINEZ et al., 2002; Jones et al., 2005). Our results are in agreement with those studies, showing that generally there is no substantial spatial genetic clustering at the individual level in both stands. However, there are clear differences between the stands in a magnitude of the spatial structure as well in a shape of the correlograms.

Assuming that Woziwoda was established using seedtree method, the autocorrelation in Woziwoda could result from establishment history. In such a case, a stand regenerates from seeds coming from a few seed donors and if seed dispersal is relatively limited, a strong spatial structure is expected (KNOwLES et al., 1992). Nonetheless, in wind-pollinated species, such as Scots pine, gene flow through pollen is extensive and outcrossing exceeds $90 \%$ (e.g. MUONA and HARJU, 1989; BuRCZYK, 1998; WASIELEWSKA et al., 2005). Hence, spatial autocorrelation observed in naturally regenerated stands may reflect spatial clumping of individuals not more related than half-sibs. Furthermore, in Scots pine seed movement, especially in open areas (as clear-cut), can be intensive (YAZDANI et al., 1989; YAZDANI and LINDGREN, 1992), causing to some degree mixing of seeds from several sources. Therefore in Woziwoda a family structure should be rather weak and can be additionally weakened if seed donors were numerous, including off- site trees. Also, the decrease of stand density as an effect of forest management and/or natural selection (namely self-thinning, TAKAHASHI et al., 2000) could finally shape the observed not significant spatial autocorrelation (EPPERSON, 1992).

In Stara Brda the spatial clumping of alleles was more distinctly pronounced as compared to Woziwoda, although the correlogram indicated a more irregular relationship between relatedness and the distance between individuals. At least two phenomena could explain a non-monotonic decay of relatedness together with distance. On one hand, the spatial genetic structure present within Stara Brda stand might be characterized by large genetic patches due to relatively intensive gene flow through seeds and pollen. In such a case, when size of the actual genetic patches approaches or even exceeds the size of the sample plot, the observed correlogram would reflect the within-patch rather than the within-population spatial genetic structure. On the other hand, it should be stressed that the study plot in Stara Brda has an irregular longed shape (c.a. $150 \mathrm{x}$ $45 \mathrm{~m}$ ). This makes a strong 'edge' effect and causes the correlogram to be difficult to interpret (SOKAL and WARTENBERG, 1983). However, when focusing on the first four distance classes (i.e. up to 36 meters only), the cline-like pattern of genetic variation appears visible. Such a fine-scale structure could be the result of colonization of a habitat from a few small genetic sources, such as the oldest individuals growing within the stand. The hypothesis of the limited size of parental population in Stara Brda is supported by the estimate of the effective population size, which is about one-half of that observed for Woziwoda. Additionally, numerous simulation studies have shown that even in case of limited gene flow, dozens of generations are needed to create substantial and quasi-stable genetic structure (SOKAL and WArtenberg, 1983; EpPERSON, 1995; HARDy and VEKEMANs, 1999). Thus, a non-stationary state due to colonization of a new habitat could further explain the irregular correlogram for Stara Brda. The lack of stability may also be a reason of not significant spatial autocorrelation observed in Woziwoda, of which detailed history is unknown.

The observed genetic structure of studied stands may enlighten some general aspects of the biology of Scots pine. Woziwoda is a qualified seed stand and its structure has been strongly influenced by a silvicultural management, for example intensive selection cutting. On the other hand, Stara Brda is a dense, uneven aged and younger stand, established without any human impact. In spite of such strong differences there were only slight differences either in genetic diversity and spatial genetic structure. Moreover, it is also probable that any differences resulted from a different establishment history will blur rapidly after few generations (TAKAHASHI et al., 2000).

\section{Acknowledgements}

This study was financially supported by the Polish Ministry of Science and Higher Education (grant no. 5 P06H 042 15). 


\section{References}

BURCZYK, J. (1996): Variance effective population size based on multilocus gamete frequencies in coniferous populations: an example of a Scots pine clonal seed orchard. Heredity 77: 74-82.

BURCZYK , J. (1998): Mating system variation in a Scots pine clonal seed orchard. Silvae Genet. 47: 155-158.

Cheliak, W. M. and J. A. Pitel (1984); Techniques for starch gel electrophoresis of enzymes from fores tree species. Information Report PI-X-42 Petawawa National Forestry Institute.

Chung, M. Y. and M. G. Chung (2004): Spatial genetic structure in populations of Quercus mongolica var. grosseserrata (Fagaceae) from southern Korea. Can. J. Bot. 82: 1402-1408.

ClifF, A. D. and J. K. ORD (1981): Spatial processes: Models and applications. London, Pion.

Conkle, M. T., P. D. Hodgskiss, L. B. Nunnally and S. C. HUNTER (1982): Starch gel electrophoresis of conifer seeds: a laboratory manual. USDA Forest Service, General Technica Report PSW-64, PSW-64, 18pp.

DvorNYK, V. (2001): Genetic variability and differentiation of geographically marginal Scots pine populations from Ukraine. Silvae Genet. 50: 64-69.

Dvornyk, V., A. Sirvio, M. Mikkonen and O. SAvolainen (2002): Low nucleotide diversity at the pal1 locus in the wildly distributed Pinus sylvestris. Mol. Biol. Evol. 19: 179-188.

England, P. R., J.-M. Cornuet, P. Berthier, D. A. TallMON and G. LUIKART (2006): Estimating effective population size from linkage disequilibrium: severe bias in small samples. Conservation Genetics 7: 303-308.

EPPERSON, B. K. (1992): Spatial structure of genetic variation within populations of forest trees. New Forests 6 : 257-278.

Epperson, B. K. (1995): Spatial Distributions of Genotypes Under Isolation by Distance. Genetics 140: 1431-1440.

EPPERSON, B. K. (2004): Multilocus estimation of genetic structure within populations. Theor. Pop. Biol. 65: 227-237.

EPPERSON, B. K. (2005): Estimating dispersal from short distance spatial autocorrelation. Heredity 95: 7-15.

EPPERSON, B. K. and R. W. AllaRD (1989): Spatial autocorrelation analysis of the distribution of genotypes within populations of lodgepole pine. Genetics 121: 369-377.

Epperson, B. K. and M. G. CHung (2001): Spatial genetic structure of allozyme polymorphisms within populations of Pinus strobus (Pinaceae). American Journal of Botany 88: 1006-1010.

GebureK, T. (2005): Sexual reproduction in forest trees, pp. 171-198. In: Conservation and management of forest genetic resources in Europe, edited by T. GEBUREK and J. TuroK, Arbora Publishers, Zvolen.

Goncharenko, G. G., V. E. Padutov and A. E. Silin (1994a): Construction of genetic maps for some eurasian coniferous species using allozyme genes. Biochimical Genetics 32: 223-236.

Goncharenko, G. G., V. E. Padutov and A. E. Silin (1994b): Allozyme variation in natural populations of Eurasian pines. III. Population structure, diversity, differentiation and gene flow in central and isolated populations of Pinus sylvestris L. in Eastern Europe and Siberia. Silvae Genet. 43: 119-132.
Gonzalez-Martinez, S. C., S. Gerber, S. Cervera, J. M. Martinez-Zapater, L. Gil and R. Alia (2002): Seed gene flow and fine-scale structure in a Mediterranean pine (Pinus pinaster Ait.) using nuclear microsatellite markers. Theor. Appl. Genet. 104: 1290-1297.

GOUDET, J. (1995): FSTAT (vers. 1.2): a computer program to calculate F-statistics. J. Hered. 86: 485-486.

Gullberg, U., R. YAZDANI, D. RUdin and N. RYMAN (1985): Allozyme variation in Scots pine (Pinus sylvetris L.) in Sweden. Silvae Genet. 34: 193-201.

HARDY, O. J. and X. VeKEMANS (1999): Isolation by distance in a continuous population: reconclination between spatial autocorrelation analysis and population genetics models. Heredity 83: 145-154.

HuDson, R. R. (1985): The sampling distribution of linkage disequilibrium under an infinite allele model without selection. Genetics 109: 611-631.

Jones, F. A., J. L. Hamrick, C. J. Peterson and E. R. SQUIERS (2005): Inferring colonization history from analyses of spatial genetic structure within populations of Pinus strobus and Quercus rubra. Mol. Ecol. 15: 851-861.

KÄRKKÄINEN, K. and O. SAVOLAINEN (1993): The degree of early inbreeding depression determines the selfing rate at the seed stage: model and results from Pinus sylvestris (Scots pine). Heredity 71: 160-166.

Knowles, P., D. J. Perry and H. A. Foster (1992): Spatial genetic structure in two tamatack (Larix laricina (Du Roi) K. Koch.) populations with differing establishment histories. Evolution 46: 572-576.

Koelewijn, H. P., V. Koski and O. Savolainen (1999): Magnitude and timing of inbreeding depression in Scots pine (Pinus sylvestris L.). Evolution 53: 758-768.

LEONARDi, S. and P. Menozzi (1996): Spatial structure of genetic variability in natural stands of Fagus sylvatica L. (beech) in Italy. Heredity 77: 359-368.

LI, C. C. and D. G. Horvitz (1953): Some methods of estimating the inbreeding coefficient. Am. J. Hum. Genet. 5: $107-117$.

Lindgren, D., L. Paule, S. Xihuan, R. Yazdani, U. SEgerstrom, J.-E. WALlin and L. LeJDEBro (1995): Can viable pollen carry Scots pine genes over long distances. Grana 34: 64-69.

Loiselle, B. A., Sork, V. L., Nason, J. and Graham, C. (1995): Spatial genetic structure of a tropical understorey shrub, Psychotria offcinalis (Rubiaceae). Am. J. Bot. 82: 1420-1425.

Mitton, J. B., M. C. Grant and A. M. Yoshino (1998): Variation in allozymes and stomatal size in pinyon (Pinus edulis, Pinaceae), associated with soil moisture. Am. J. Bot. 85: 1262-1265.

MuONA, O. and A. HARJU (1989): Effective population sizes, genetic variability, and mating system in natural stands and seed orchards of Pinus sylvestris. Silvae Genet. 38: 221-228.

Niebling, C. R., K. Johnson and H. D. Gerhold (1987): Electrophoretic analysis of genetic linkage in Scots pine (Pinus sylvestris L.). Biochimical Genetics 25: 803-814.

Parker, K. C., J. L. Hamrick, A. J. Parker and J. D. NASON (2001): Fine-scale genetic structure in Pinus clausa (Pinaceae) populations: effects of disturbance history. Heredity 87: 99-113.

Peakall, R., M. Ruibal and D. B. Lindenmayer (2003): Spatial autocorrelation analysis offers new insights into gene flow in the Australian bush rat, Rattus fuscipes. Evolution 57: 1182-1195. 
Prus-Glowacki, W., L. URBANIAK and M. ŻUbrowska-GIL (1993): Allozyme differentiation in some european populations of Scots pine (Pinus sylvestris L.). Genetica Polonica 34: 159-176.

Prus-Glowacki, W. and B. R. StePhan (1994): Genetic variation of Pinus sylvestris from Spain in relation to other european populations. Silvae Genet. 43: 7-14.

Rousset, F. (2000): Genetic differentiation between individuals. J. Evol. Biol. 13: 58-62.

Rudin, D. and I. EkBerg (1978): Linkage studies in Pinus sylvestris L. - using macro gametophyte allozymes. Silvae Genet. 27: 1-12.

SHAPсотт, A. (1995): The spatial genetic structure in natural populations of the Australian temperate rainforest tree Atherosperma moschatum (Labill) (Monimiaceae). Heredity 74: 28-38.

SLAtKIN, M. (1985): Gene flow in natural populations. Ann. Rev. Ecol. Syst. 16: 393-430.

Smouse, P. E. and R. PeAKall (1999): Spatial autocorrelation analysis of individual multiallele and multilocus genetic structure. Heredity 82: 561-573.

SoKAL, R. R. and D. E. WARTENBERG (1983): A test of spatial autocorrelation analysis using an isolation-by-distance model. Genetics 105: 219-237.

SPIESS, E. B. (1989): Genes in populations. John Wiley \& Sons, Inc., New York.

StreifF, R., T. LabBe, R. Bacilieri, H. SteinkellneR, J. Glossl and A. KREMER (1998): Within-population genetic structure in Quercus robur L. and Quercus petraea (Matt.) Liebl. assessed with isozymes and microsatellites. Mol. Ecol. 7: 318-238.

SzMidT, A. E. and O. MuONA (1989): Linkage relationships of allozyme loci in Pinus sylvestris. Hereditas 111: 91-97.

TAKahashi, M., M. Mukouda and K. Koono (2000): Differences in genetic structure between two Japanese beech (Fagus crenata Blume) stands. Heredity 84: 103-115.

VeKemans, X. and O. J. HARDY (2004): New insights from fine-scale spatial genetic structure analyses in plant populations. Mol. Ecol. 13: 921-935.

WAPLES, R. S. (1991): Genetic Methods for Estimating the Effective Size of Cetacean Populations. Rep. Int. Whal. Commn. 13: 279-300.

WAPLES, R. S. (2006): A bias correction for estimates of effective population size based on linkage disequilibrium at unlinked gene loci. Conservation Genetics 7: $167-184$.

WASIELEWSKA, M., M. KLEMM and J. BuRCZYK (2005): Genetic diversity and mating system of Scots pine plus trees. Dendrobiology 53: 57-62.

WEIR, B. S. and W. G. HILL (1980): Effect of mating structure on variation in linkage disequilibrium. Genetics 95: $477-488$.

WRIGHT, S. (1943): Isolation by distance. Genetics 28: 114-138.

YAzDANI, R., O. MuonA, D. Rudin and A. SzMidT (1985): Genetic structure of a Pinus sylvestris L. seed-tree stand and naturally regenerated understory. Forest Sci. 31: 430-436.

YAZDANi, R., D. LindGren and S. StewART (1989): Gene dispersion within a population of Pinus sylvestris. Scand. J. For. Res. 4: 295-306.

YAZDANI, R. and D. LiNDGREN (1992): Gene dispersion after natural regeneration under a widely-spaced seedtree stand of Pinus sylvestris (L.). Silvea Genet. 41: 1-5.
YeH, F. C., R.-C. YANG, T. B. J. Boyle, Z.-H. Ye and J. X. MAO (1997): POPGENE, the user-friendly shareware for population genetic analysis. Molecular Biology and Biotechnology Centre, University of Alberta, Canada.

\section{Appendix}

Here we explain the relationship between the relatedness coefficient $r_{\mathrm{S}}$ derived by STREIFF an co-authors (1998) and the unweighted autocorrelation coefficient $r_{S \& P}$. introduced by SMOUSE and PEAKALL (1999). For the $h$-th distance class the respective single-locus multiallele coefficients are defined as:

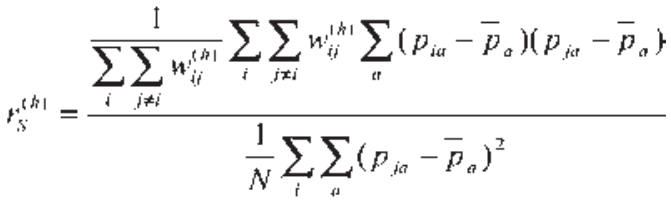

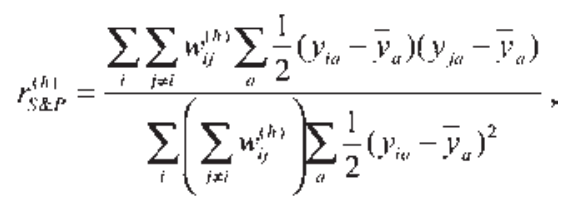

where $w_{i j}^{(h)}$ equals 1 when the distance between the $i$-th and the $j$-th individual falls into the $h$-th distance class, and 0 otherwise; $p_{i a}$ and $p_{j a}$ are the frequencies of the $a$-th allele in the $i$-th and the $j$-th individual, respectively; $\bar{p}_{a}$ is a sample frequency of the $a$-th allele; $y_{i a}$ and $y_{j a}$ are scores for the $a$-th allele in the $i$-th and the $j$-th individual, respectively (equal to a number of copies of the $a$-th allele); $\bar{y}_{a}$ is an average score of the $a$-th allele and $N$ is a sample size.

First one can see that

$$
y_{i a}=2 p_{i a} \text { and } \bar{y}_{a}=\frac{2 n_{a n}+n_{a}}{N}=2 \bar{p}_{i r}
$$

where $n_{a a}$ is a number of homozygotes with the $a$-th allele and $n_{a-}$ is a number of heterozygotes having the $a$-th allele. Hence, for the $h$-th distance class $r_{S \& P}$ can be re-written as:

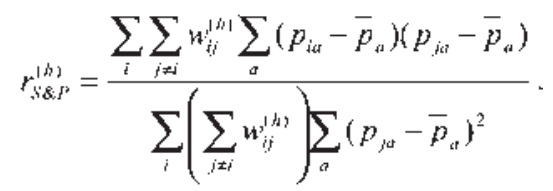

Although very close, the autocorrelation coefficient $r_{S \& P}$ formulated in that way is not equal to the relatedness coefficient $r_{S}$, because the sum of squares related to the variance (denominator) of $r_{S \& P}$ is weighted by a number of times the $i$-th individual is included into the computation of the sum of squares related to the covariance (numerator). This makes the denominator (thus the variance-related component) to be the $h$-th distance interval-dependent, and not the entire sample-dependent, as in the case of $r_{S}$ coefficient. Nonetheless, it can be shown that $r_{S \& P}$ coefficient is asymptotically equal to the $r_{S}$ coefficient, when the studied population consists of infinitely many uniformly distributed individuals. In this particular case all individuals incorporate equal, say $c^{(h)}$, number of times into the $h$-th distance interval, 
and hence for every $i$-th individual $\sum_{j \neq i} w_{i j}^{(h)}=c^{(h)}$, resulting in:

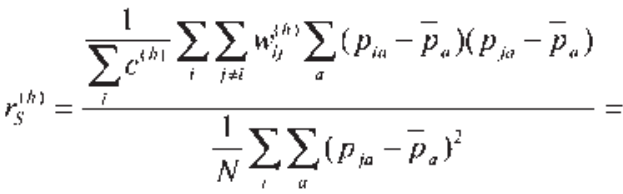

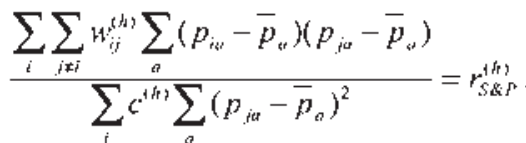

In practice, given moderate to large sample sizes (say 100 individuals or more), an approximately uniform distribution of individuals and a regular shape of the habitat (e.g. circle, square, etc.), one can expect that $r_{S} \approx r_{S \& P}$. Violating these conditions, on the other hand, can cause that the relatedness (i.e. likeness) between a given pair of genotypes estimated with $r_{S \& P}$ can differ substantially depending on the distance between individuals. However, this does not apply to $r_{S}$ coefficient.

It is also worth noting that the relatedness coefficient introduced by Streiff and co-authors (1998) reduces to well known Moran's I coefficient for bi-allelic locus.
Additionally, $r_{S}$ coefficient can be easily transformed into the kinship coefficient as given by LOISELLE et al. (1995). For this purpose one can note that for any number of alleles at a locus the measure of variance (i.e. the denominator of $r_{S}$ ), is equal to:

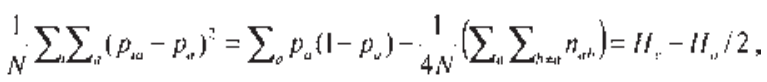

where $n_{a b}$ stands for the observed number of heterozygotes made of the $a$-th and the $b$-th allele, and $H_{e}$ and $H_{o}$ is expected and observed heterozygosity, respectively. Because the kinship coefficient proposed by LOISELLE et al. (1995), and $r_{S}$ differ only in their denominators, the ratio of the coefficients is actually equal to the ratio of their denominators, and equal to:

$$
\frac{f}{r_{s}}=\frac{H_{r}, H_{n} / 2}{H_{r}}=\frac{\mathrm{i}+F}{2}
$$

where $F$ is the within-population inbreeding coefficient. The above property is a desired relation between kinship and relatedness measures, as discussed previously for bi-allelic locus (HARDY and VEKEMANS, 1999). In the case of $r_{S \& P}$ coefficient, the above relationships holds only asymptotically, under conditions mentioned above.

\title{
Inbreeding Depression in the Full-sib Offspring of Populus nigra L.
}

\author{
By V. Benetka*), M. PospíšKová, F. VRÁtnÝ and M. Tkaczyková \\ Silva Tarouca Research Institute for Landscape and Ornamental Gardening Průhonice, \\ Publ. Res. Inst.CZ - 25243, Czech Republic
}

(Received 25 ${ }^{\text {th }}$ January 2007)

\begin{abstract}
Controlled pollination was carried out in the species Populus nigra L. in a greenhouse on isolated branches between sisters and a brother - inbreeding $(\mathrm{S} \times \mathrm{B})$. Female trees (sisters) were also exposed to open pollination (OP) in the neighbourhood of a male tree (brother) and other Populus nigra trees in the vicinity. The analysis of 11 microsatellites was done in the offspring from the inbreeding $(\mathrm{S} \times \mathrm{B})$ and from the OP. In OP offspring was found $20-76 \%$ of viable individuals that were coming from pollination with brother's pollen (spontaneous inbreeding). These individuals were separated from the offspring. In a randomised field trial the offspring were evaluated for two years. Fitness decreased in S x B offspring, traits of plant height, trunk diameter, height increment and resistance to Melampsora larici-populina Kleb. were lower in comparison with those of OP offspring. A coefficient of inbreeding depression $(\delta)$ ranged from 0.373 to 0.034 . The significance of differences
\end{abstract}

*) Corresponding author: VoJTЕ̌CH BenetKA. Tel.: +420 296528 253, Fax: +420 267750 440. E-mail address: benetka@vukoz.cz between the offspring from $\mathrm{S} \times \mathrm{B}$ and $\mathrm{OP}$ of the particular sisters was proved.

About $30 \%$ of homozygous microsatellite loci were identified in inbred S x B offspring, which was more than in OP offspring. This difference was significant in the offspring of three sisters; it was not significant in the offspring of one sister. This trend corresponded to the results of growth traits.

Key words: inbreeding depression, open pollination, spontaneous inbreeding, microsatellites, Populus nigra L.

\section{Introduction}

Populus nigra is a species whose populations are more and more fragmented. As a dioecious outbreeding species, a certain level of genetic load is expected which could make it sensitive to a sudden increase of inbreeding (HEINZE and LEFÈVRE, 1999). Inbreeding is a fertilization system which involves the breeding together of individuals more closely related. In diminishing subpopulation, the probability of the fusion of recessive alleles bearing possible deleterious mutations increases. Basic 